\title{
FACTORS OF RESILIENCE, WISDOM AND SELF-EFFICACY AS POSITIVE RESOURCES OF LEADERS IN SAMPLE OF LATVIAN BUSSINESS MANAGERS
}

\author{
Guna Svence \\ Riga Teacher Training and Education Management Academy, Riga, Latvia \\ E-mail: gunasvence@rpiva.Iv \\ Vineta Greaves \\ VCG SIA ("VCG"), Riga, Latvia \\ E-mail: vineta.grivza@vcg.lv
}

\begin{abstract}
The aim of this study is to investigate relationships between positive psychology resources - resilience, general self-efficacy and wisdom dimensions - cognitive, reflective and affective in different level business leaders and to investigate differences between two groups of leaders - with higher general self-efficacy and lower general self-efficacy. The study was carried out based on theories of psychological resources. Resources not only buffer against the potentially harmful stress effects of the demands of working life, but may promote development and optimal performance, which is necessary for leaders to be able to meet increasing demands of their role. 83 respondents (57 women, 26 men) different level business leaders participated in the study.

Results showed that in sample of leaders group there are statistically significant relationships between resilience and self-efficacy, resilience and reflective wisdom dimension, self-efficacy and wisdom reflective and cognitive dimensions. Results of difference analysis showed that there are differences in levels of psychological resources between high general self-efficacy leaders and low general self-efficacy leaders. High general self-efficacy leaders showed higher results in all tested psychological resources and statistically significant differences between two groups were reported in resilience. Results suggest that low self-efficacy leaders would be less able to adapt to uncertainty, and/ or bounce back or recover from stress. Research results suggest that higher level of general self-efficacy is related to higher levels of resources - resilience and wisdom.
\end{abstract}

Key words: psychological resources, resilience, self-efficacy, wisdom.

\section{Introduction}

The study of leadership in organizations has been prevalent since the beginning of the 19th century and thousands of research studies have focused on leadership phenomenon (Yukl, 1989) in part to enhance our ability to predict leadership effectiveness (Hendricks \& Payne, 2007).

Today's leaders face unprecedented challenges as organizations struggle to adapt to everaccelerating rates of change both internally and with the external environment (Hannah, Avolio, Luthans, \&Harms, 2008). Hannah et al (Hannah, Avolio, Luthans, \&Harms, 2008) emphasizes that many authors in their works (Avolio and Luthans, 2006; Hooijberg et al., 1997; Lord and Hall, 2005;) stress that such change challenges not only the knowledge, skills and abilities of leaders, but also the self-conceptualizations of their leadership capabilities and psychological resources to meet the ever increasing demands of their roles. 
While there are no quick fixes to these complex and challenging problems, positive psychology suggests that the potential for a more hopeful, productive, and satisfying future can emerge for people who are struggling to find their way through these tough times (Froman, 2010). In accordance with Fredrickson's broaden-and-build theory, those individuals who have more positive psychological resources are expected to grow more effectively or to broaden themselves and build out additional personal resources to perform (Avolio, Walumbwa, \& Weber, 2009).

Luthans, Norman, Avolio, \& Avey (2008) in their work state that to date, the positive psychological constructs that have been determined to best meet the Positive organizational behaviour (POB) and its derivative concept of psychological capital or PsyCap are hope, resilience, optimism, and self-efficacy (Luthans, 2002a; Luthans et al., 2004; Luthans\& Youssef, 2004; Luthans \& Youssef, 2007; Luthans, Youssef et al., 2007) and emphasize that other positive psychological constructs such as work engagement (Schaufeli \& Bakker, 2004; Schaufeli \& Salanova, 2007), psychological well-being (Wright \& Cropanzano, 2000, 2004), psychological ownership (Avey, Avolio, Crossley, $\&$ Luthans, in press), wisdom, courage, and forgiveness (e.g., see Luthans, Youssef et al., 2007, Chapters 6 and 7) could and likely will be included in the future.

There are scientific studies that examine relationships of resilience and specific self-efficacy. Luthans, Norman, Avolio, \& Avey (2008) in their work examine the following positive psychological constructs or resources: hope, resilience, optimism and efficacy and note that psychological capital (PsyCap) has been specifically defined as "an individual's positive psychological state of development that is characterized by: (1) having confidence (self-efficacy) to take on and put in the necessary effort to succeed at challenging tasks; (2) making a positive attribution (optimism) about succeeding now and in the future; (3) persevering toward goals and, when necessary, redirecting paths to goals (hope) in order to succeed; and (4) when beset by problems and adversity, sustaining and bouncing back and even beyond (resiliency) to attain success" (Luthans, Youssef et al., 2007, p. 3).

However studies that examine relations of resilience, general self-efficacy and wisdom dimensions we did not find. Therefore in contrast to the psychological capital (PsyCap) theory, we were interested to examine relationships between general self-efficacy, resilience and wisdom dimensions.

Resilience gives the leader an ability to create a vision, challenge the process, and allow potential to unfold (Baldwin, Maldonado, Lacey, \& Efinger, 2004).

In circumstances where leaders are constantly overloaded with information, wisdom becomes a crucial characteristic for leaders to survive the fierce competition, i.e., leadership wisdom is the ability to put into action the most appropriate behaviour, a choice based on the realization of what is valuable in life, for oneself and others (Wei \& Yip, 2008).

The purpose of this study was to answer the question - whether there are relationships between the leaders' positive psychological resource factors - general self-efficacy, resilience and wisdom, and to investigate the differences in self-efficacy, resilience and wisdom between two groups of leaders -1 ) with lower general self-efficacy and 2) higher general self-efficacy.

\section{Problem of Research}

Gorgievski, Halbesleben and Bakker in their work (2011) state that key resource theories generally focus on single or multiple individual difference variables (resources) that are considered key for effective adaptation and management of the demands of life, such as theories on self-referent beliefs like self-efficacy (Bandura, 1997), dispositional optimism (Carver \& Scheier, 1998), and psychological capital, a composite of optimism, hope, self-esteem, and self-efficacy (Luthans \& Youssef, 2004). Key resource theories in occupational and organizational psychology have been used extensively to explain individual differences in resilience to job stress. Authors highlight that resources not only act as a buffer against the potentially harmful stress effects of the demands of working life, resources have intrinsic value, and the active search for gaining and increasing resources has a motivating effect, as such, resources form an excellent basis for flourishing in the workplace and optimal performance (Gorgievski, Halbesleben, Bakker, 2011).

According to Wood \& Bandura (1989) "self-efficacy refers to beliefs in one's capabilities to mobilize the motivation, cognitive resources, and courses of action needed to meet given situational 
demands" (Wood \& Bandura, 1989, p. 408). Chen, Gully \& Eden (2009) in their work state, that restrictive words "given situational demands" in Wood's \& Bandura's definition have given self-efficacy a narrow focus, therefore there are researchers, who have become interested in the more generality dimension of self-efficacy (general self-efficacy). According to Chen, Gully \& Eden (2009) general self-efficacy ,captures differences among individuals in their tendency to view themselves as capable of meeting task demands in a broad array of contexts" (Chen, Gully \& Eden ,2009, p.63).

Chen and colleagues (Chen, Gully, Eden, 2009) observe in their study that majority of selfefficacy researchers continue to focus on specific self-efficacy and ignore the general dimension of self-efficacy. Taking into account that jobs and roles in organizations are becoming increasingly broad, complex, and demanding, high general self-efficacy is a valuable resource for organizations because it can maintain employees' work motivation throughout rapidly changing and stressful job demands and circumstances and act as a buffer for them against the potentially demotivating impact of failure (Chen, Gully, Eden, 2009).

Hannah et al (Hannah, Avolio, Luthans, \&Harms, 2008) notes, that research has shown that leaders with higher levels of self-efficacy (Krueger \& Dickson, 1993) and general efficacy (Betz and Hacket, 1986; Lent and Hackett, 1987) focus on opportunities to pursue challenges, while those with lower efficacy focus on risks to be avoided.

Hannah et al. (Hannah, Avolio, Luthans, \& Harms, 2008) propose that future research should investigate leader's efficacy development as a cycle of positive development. Authors propose that leaders with higher efficacy will increase their exposure to developmental events and experience a continuous widening (generalization) of their domain of leader efficacy over time via adaptive selfreflection factors. Hannah et al (2008) emphasizes, that leaders' efficacy beliefs are perceptions of and can thus be distinct from their actual capabilities. They also suggest that the efficacy beliefs of highly self-aware leaders will be based on realistic assessments of their actual capabilities (Hannah, Avolio, Luthans, \&Harms, 2008).

Küpers \& Statler (2008) note, that organizational theorists have started to use the concept of practical wisdom to describe how strategists and leaders deal ethically and effectively with uncertainty. By example, Clegg and Ross Smith (2003) notes, that wisdom may be the essential management virtue, as management is limited by great depths of uncertainty and ignorance within which it is constituted (Küpers \& Statler, 2008).

Monika Ardelt (2004) suggests, that wise individuals can face the most difficult situations with equanimity, because they are aware and can accept the reality of the present moment and proposes, that the simultaneous presence of cognitive, reflective, and affective personality characteristics is necessary but also sufficient for a person to be considered wise (Ardelt, 2004). According Ardelt (2003), the cognitive dimension of wisdom refers to a person's ability to understand life, to comprehend the significance and deeper meaning of phenomena and events, including inherent limits of knowledge, and of life's unpredictability and uncertainties. In order to have a deeper understanding of life, one needs to engage in reflective thinking by looking at phenomena and events from many different perspectives to develop self-awareness and self-insight, thereby gradually reducing one's self-centeredness, subjectivity, projections, and increase one's insight into the true nature of things (Ardelt, 2003).

It is the apparent contrast between the attributes attendant on leaders with high levels of selfefficacy and those with lower levels that aroused authors interest and caused to search more deeply into the concepts that accompany this contrast including, but not limited, the essence of wisdom, resilience.

\section{Research Focus}

The main idea was to investigate leader's psychological resources - resilience, general selfefficacy and wisdom dimensions - cognitive, reflective and affective dimension.

Research questions:

1. Is there statistically significant relationship between leader positive resources factors self-efficacy, resilience and wisdom? 
2. Which additional variables (age, gender, work experience, education, responsibility level) correlate the most with the leader's positive psychological resource factors - general self-efficacy, resilience, wisdom?

3. Are there statistically significant differences between two groups of leaders - with high general self-efficacy and low general self-efficacy in wisdom, resilience and self-efficacy scores?

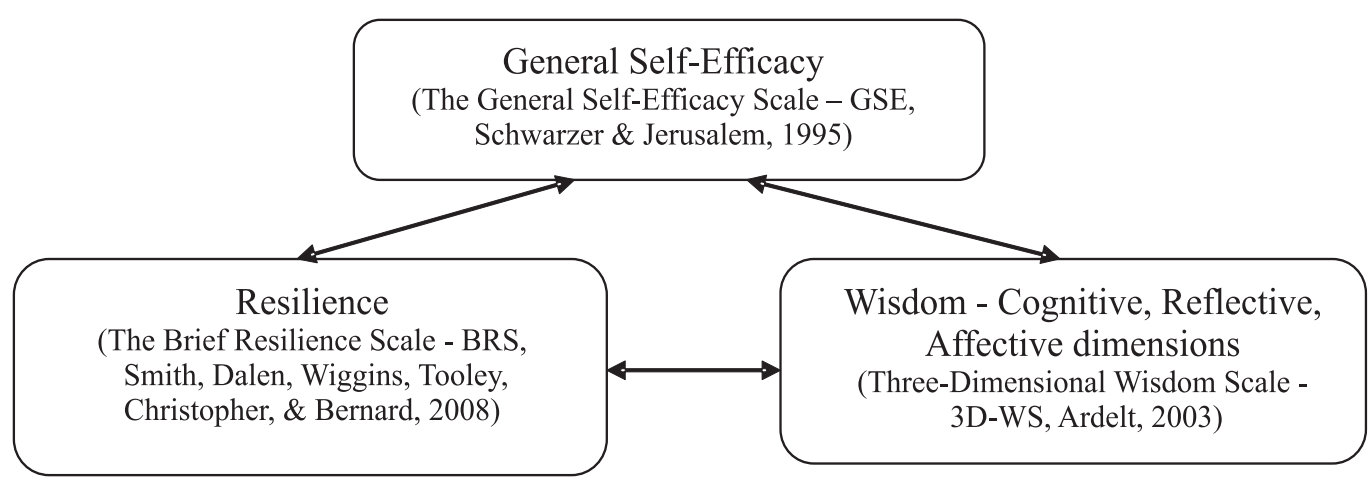

\section{Figure 1: Research theoretical framework. Relations between Leader's positive resource factors.}

Schwarzer and Hallum (2008) note that a general sense of self-efficacy refers to global confidence in one's coping ability across a wide range of demanding or novel situations (Schwarzer and Hallum, 2008). Luszczynska and colleagues (Luszczynska, Gutiérrez-Doña, Schwarzer, 2005) in their study of general self-efficacy in various domains of human functioning emphasise that self-efficacy is not only of a task-specific nature, but is also the belief in one's competence to tackle novel tasks and to cope with adversity in a broad range of stressful or challenging encounters, as opposed to specific self-efficacy. Across the five countries (Costa Rica, Germany, Poland, Turkey, and the USA) highest positive relations of general self-efficacy with optimism, self-regulation, and self-esteem were found, whereas the highest negative associations emerged with depression and anxiety (Luszczynska, Gutiérrez-Doña, Schwarzer, 2005).

Monika Ardelt (2004) believes that a deeper understanding of life is only possible if you can perceive reality as it is, without significant distortions and proposes that the simultaneous presence of cognitive, reflective, and affective personality characteristics is necessary but also sufficient for a person to be considered wise. Cognitive dimension of wisdom refers to the desire to know the truth and attain a deeper understanding of life, which includes knowledge and acceptance of the positive and negative aspects of human nature, of the inherent limits of knowledge, and of life's unpredictability and uncertainties. The reflective component of wisdom represents self-examination, self-awareness, self-insight and the ability to look at phenomena and events from different perspectives, and affective component consists of a person's sympathetic and compassionate love for others (Ardelt, 2004).

Luthans et al. (Luthans, Norman, Avolio, \& Avey, 2008) state that resilience as adapted to the workplace has been defined as the "positive psychological capacity to rebound, to 'bounce back' from adversity, uncertainty, conflict, failure, or even positive change, progress and increased responsibility" (Luthans, 2002a, p. 702). The definition of POB resilience also takes into account the need to bounce back even from positive but potentially overwhelming events such as greatly increased responsibility and accountability, as these challenges may be viewed as threats by those who lack resilience but as challenging opportunities by those who possess considerable resilience (Youssef \& Luthans, 2007). Resilience cannot be limited to just a reactive capacity that is expressed in times of adversity. Resilience permits adversities and setbacks to be viewed as opportunities for learning, growth, and development, engages creative and flexible adaptive mechanisms, guided by ethical values and strong belief systems, toward the achievement of personally and organizationally meaningful goals (Youssef \& Luthans, 2007). Authors also note that resilience has also been found to be related to work attitudes of satisfaction, happiness, and commitment (Youssef \& Luthans, 2007). 


\section{Methodology of Research}

The study data were analyzed in response to the research questions and identify correlations between positive resource factors - resilience, general self-efficacy and wisdom cognitive, reflective and affective dimensions, identify relations between positive resource factors and additional variables (age, gender, work experience, education, responsibility level) and identify positive resource factors differences between two groups of leaders - with higher general self-efficacy and lower general self-efficacy.

\section{General Background of Research}

The main idea of the study is to examine if there is correlation between general self-efficacy, resilience and wisdom, and to investigate the differences in two factors: resilience and wisdom between two groups of leaders -1) with lower general self-efficacy and 2) higher general self-efficacy.

The aim of the study: theoretically and empirically investigate leader's positive psychological resource factors and find out relations between them, and to study the differences between the two groups of leaders - with higher general self-efficacy and lower general self-efficacy.

Object of the study: interrelations between the leader positive psychological resource factors resilience, general self-efficacy and wisdom dimensions, and differences of positive psychological resource factors.

\section{Sample of Research}

83 respondents $(\mathrm{M}=39.63 ; \mathrm{SD}=7.70)$ participated in the study: 57 female $(\mathrm{M}=39.49 ; \mathrm{SD}=8.05)$ and 26 male $(M=39.92 ; S D=7.01)$. The study took place in Latvia, the survey was posted on the internet site www.visidati.lv and invitations to participate and complete the survey were sent to different level leaders of different business companies with request to pass on this invitation to their friends or business contacts. Respondents were informed that this is survey to test a leader's positive resource factors and they did not know which exact resources are examined in this survey. Respondents were offered a reward for participating - the opportunity to receive analysis of their results in comparison with the other study participants. Respondents are business leaders of different levels from various industries: banking, finance, accounting, information technology, telecommunications, marketing, advertising and media, law, manufacturing, construction, logistics, hotel business, tourism, customer service, etc. $80 \%$ of respondents live in Riga, others - mainly in close surroundings of Riga.

The methodology of the study is based on quantitative methods. Three-dimensional Wisdom Scale (3D-WS, Ardelt, 2003), The Brief Resilience Scale (Smith, Dalen, Wiggins, Tooley, Christopher, \& Bernard, 2008) and The General Self-Efficacy Scale (Schwarzer \& Jerusalem, 1995) was used in research. Spearman correlation analysis and univariate analysis of variance with Scheffe post-hoc test was used to test relationships, while differences were tested by Mann-Whitney test.

\section{Instrument and Procedures}

Empirical methods - survey methods:

1. The Brief Resilience Scale - BRS (Smith, Dalen, Wiggins, Tooley, Christopher, \& Bernard, 2008). BRS was created to assess the ability to bounce back or recover from stress. BRS represents one factor, is related to resilience resources and health-related outcomes, and BRS was consistently negatively correlated with perceived stress, anxiety, depression, negative affect, and physical symptoms.

2. Three-dimensional Wisdom Scale-3D-WS (Ardelt, 2003). Wisdom is treated as a latent variable with cognitive, reflective, and affective effect indicators. The cognitive component is assessed by items that measure an understanding of life or the desire to know the truth, what includes knowledge of the positive and negative aspects of human nature, 
tolerance of ambiguity and uncertainty, and the ability to make important decisions despite life's unpredictability and uncertainties. The reflective component measures the ability to look at phenomena and events from different perspectives and to avoid subjectivity and projections, i.e., to avoid blaming other people or circumstances for one's own situation or feelings. The affective element captures the presence of positive emotions and behaviour toward other beings, such as feelings and acts of sympathy and compassion, and the absence of indifferent or negative emotions and behaviours toward others.

3. The General Self-Efficacy Scale - GSE (Schwarzer \& Jerusalem, 1995). This scale was created to asses a general sense of perceived self-efficacy with the aim to predict coping with daily hassles as well as adaptation after experiencing all kinds of stressful life events. The scale measures optimistic self-belief, i.e., belief that one can perform novel or difficult tasks, or cope with adversity in various domains of functioning. It can be regarded as positive resistance resource factor, facilitates goal-setting, effort investment, persistence in the face of barriers and recovery from setbacks.

In this study in all scales a five-point Likert-type measures were used to obtain consistency of scales across this research, ranging either from 1 (strongly agree) to 5 (strongly disagree) or from 1 (definitely true of myself) to 5 (not true of myself).

\section{Data Analysis}

Spearman correlation analysis and univariate analysis of variance with Scheffe post-hoc test was used to test relationships, while differences were tested by Mann-Whitney test.

\section{Results of the Research}

Cronbach's alphas, descriptive statistics, and intercorrelations among the variables are presented in Table 1.

\section{Table 1. Cronbach's Alphas, Descriptive Statistics and Spearman correlations} Among Variables.

\begin{tabular}{|c|c|c|c|c|c|c|c|c|c|}
\hline \multirow[b]{3}{*}{ Variables } & \multirow{3}{*}{$\begin{array}{l}0 \\
0 \\
0 \\
\bar{c} \\
\mathbb{\pi} \\
0 \\
0 \\
0 \\
0 \\
0\end{array}$} & \multirow{2}{*}{\multicolumn{2}{|c|}{$\begin{array}{l}\text { Descriptive } \\
\text { statistic }\end{array}$}} & \multicolumn{6}{|c|}{ Spearman correlations of Positive resource factors } \\
\hline & & & & \multirow[b]{2}{*}{ 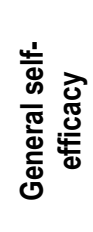 } & \multirow[b]{2}{*}{ 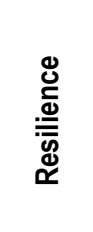 } & \multicolumn{4}{|c|}{ Three dimension wisdom scale } \\
\hline & & M & SD & & & $\begin{array}{l}\text { D 흥 } \\
\text { 홍 } \\
\text { 응 }\end{array}$ & 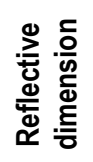 & 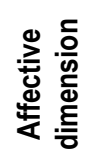 & 흉 흉 \\
\hline General self-efficacy & 0.71 & 36.43 & 3.84 & 1 & & & & & \\
\hline Resilience & 0.74 & 3.60 & 0.54 & $0.49^{* *}$ & 1 & & & & \\
\hline Cognitive dimension & 0.71 & 3.36 & 0.43 & $0.22^{*}$ & 0.13 & 1 & & & \\
\hline Reflective dimension & 0.71 & 3.59 & 0.38 & $0.30^{*}$ & $0.31^{*}$ & $0.52^{* *}$ & 1 & & \\
\hline Affective dimension & 0.61 & 3.16 & 0.45 & 0.17 & 0.15 & $0.31^{* *}$ & $0.35^{\star *}$ & 1 & \\
\hline Total wisdom score & 0.82 & 3.37 & 0.33 & $0.25^{\star}$ & 0.19 & $0.78^{\star *}$ & $0.77^{\star *}$ & $0.73^{* *}$ & 1 \\
\hline Responsibility level & - & - & - & $0.24^{*}$ & 0.13 & 0.01 & 0.17 & 0.14 & 0.12 \\
\hline Age & - & 39.6 & 7.70 & -0.04 & -0.15 & -0.18 & -0.06 & 0.01 & -0.09 \\
\hline Work experience & - & 18.22 & 8.16 & -0.09 & $-0.23^{*}$ & -0.21 & -0.13 & -0.03 & -0.15 \\
\hline Education & - & - & - & -0.09 & -0.03 & $0.24^{*}$ & 0.20 & -0.03 & 0.16 \\
\hline
\end{tabular}


First, we computed Spearman correlations to examine relations between positive resource factors: general self-efficacy, resilience, wisdom dimensions - cognitive, reflective and affective dimension, and other additional variables (age, gender, work experience - number of years, education, responsibility level). Correlation coefficients are displayed in Table 1.

The closest statistically significant correlation between positive resource factors was shown between self-efficacy and resilience $(r=0.49 ; p<0.01)$. General self-efficacy have statistically significant correlation between cognitive wisdom dimension $(r=0.22 ; p<0.05)$, reflective wisdom dimension $(r=0.30 ; p<0.05)$ and total wisdom score $(r=0.25 ; p<0.05)$. However resilience have statistically significant correlation only between reflective wisdom dimension $(r=0.31 ; p<0.05)$.

In order to analyse statistically significant correlations shown in Table 1 between positive resources further, sample was divided into 3 quartiles yielding groups of low, medium and high self-efficacy based on general self-efficacy results. Univariate analysis of variance with Scheffe Post -hoc test and Levene's Test of Equality of Error Variances was performed. Levene test showed that the variances are homogeneous $(p>0.05)$. Results of univariate analysis of variance are shown in Table 2.

Results of univariate analysis of variance (see Table 2) show that all three self-efficacy level leader groups have significantly different resilience average scores $\left(\mathrm{F}=9.38 ; \mathrm{p}<0.01 ;\right.$ partial $\eta^{2}$ $=0.190$ ), what is clearly visible in Figure 1. Self-efficacy effect size on resilience results can be assessed as large, because $\eta^{2}>0.14$ (see Cohen, 1988, p287). Low level self-efficacy leader group $(<25 \%)$ and high level self-efficacy leader group have significant differences is reflective wisdom dimension average scores $\left(\mathrm{F}=4.48 ; \mathrm{p}<0.05 ;\right.$ partial $\left.\eta^{2}=0.101\right)$. Self-efficacy effect size on reflective dimension results can be assessed as medium, because $\eta^{2}>0.06$ (see Cohen, 1988, p. 287). Results show that different level self-efficacy leader groups do not have significantly different average scores in cognitive wisdom dimension, affective wisdom dimension and total wisdom scores.

Table 2. The differences in mean and standard deviations between different selfefficacy leader groups - low level, medium level and high level.

\begin{tabular}{|c|c|c|c|c|c|c|c|c|}
\hline \multirow{3}{*}{ Variable } & \multicolumn{6}{|c|}{ Self-efficacy quartile groups } & \multirow{3}{*}{$\mathrm{F}$} & \multirow{3}{*}{$\eta 2$} \\
\hline & \multicolumn{2}{|c|}{$\begin{array}{l}\text { 1. Group - } \\
\text { low level }<25 \% \\
(n=17)\end{array}$} & \multicolumn{2}{|c|}{$\begin{array}{l}\text { 2. Group - medium } \\
\text { level } \\
\begin{array}{l}25 \%-75 \% \\
(n=53)\end{array}\end{array}$} & \multicolumn{2}{|c|}{$\begin{array}{l}\text { 3. Group- } \\
\text { high level } \\
>75 \% \\
(n=13)\end{array}$} & & \\
\hline & M & SD & M & SD & M & SD & & \\
\hline Resilience & $3.27 a$ & 0.45 & $3.60 \mathrm{~b}$ & 0.53 & $4.05 \mathrm{c}$ & 0.37 & $9.38^{* *}$ & 0.190 \\
\hline Wisdom (total) & $3.24 a$ & 0.32 & $3.38 \mathrm{a}$ & 0.34 & $3.48 \mathrm{a}$ & 0.25 & 2.16 & 0.051 \\
\hline Cognitive dimension & $3.26 a$ & 0.51 & $3.36 a$ & 0.41 & $3.45 a$ & 0.43 & 0.74 & 0.018 \\
\hline Affective dimension & $3.05 a$ & 0.38 & $3.19 a$ & 0.50 & $3.18 \mathrm{a}$ & 0.35 & 0.61 & 0.015 \\
\hline Reflective dimension & $3.41 \mathrm{a}$ & 0.36 & $3.59 a, b$ & 0.38 & $3.81 \mathrm{~b}$ & 0.28 & $4.48^{*}$ & 0.101 \\
\hline
\end{tabular}

Note. $N=83$. In accordance with Scheffe Post-hoc test results, in every row the means, which have the same subscript numeral, $d o$ not statistically significantly differ $(p>0.05) .{ }^{*} p<0.05 ; * * 0.01$.

Results in Figure 1 suggest, that different level self-efficacy level leaders have significant differences in resilience results. 


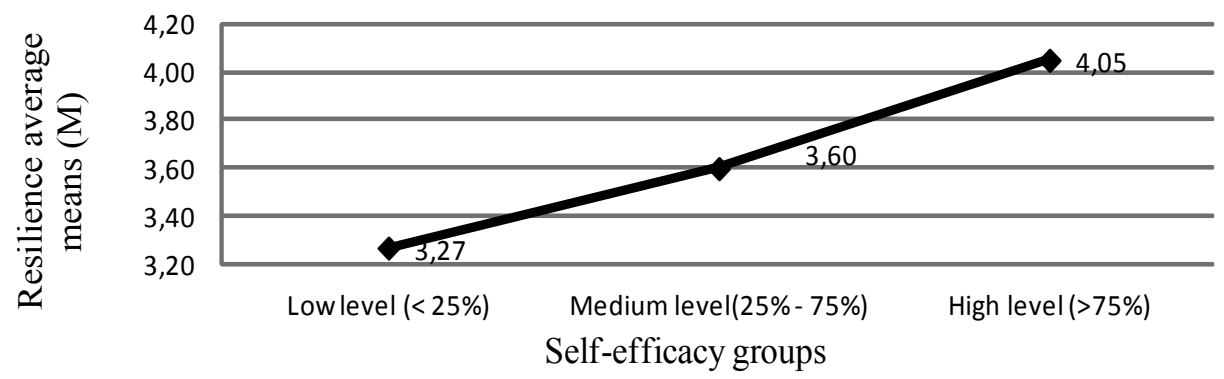

\section{Figure 1: Resilience average scores in self-efficacy quartile groups.}

Regarding correlation between leaders positive psychological resource factors and additional variables (age, gender, work experience - number of years, education, level of responsibility) Table 1 show positive statistically significant correlation between general self-efficacy and level of responsibility (number of subordinate staff) $(r=0.24 ; p<0.05)$, and positive statistically significant correlation between education level and wisdom cognitive dimension $(r=0.24 ; p<0.05)$. In contrast, negative statistically significant correlation appears between work experience and resilience $(r=-$ $0.23 ; p<0.05)$.

There were no correlations between positive resource factors and gender, and between positive resource factors and age.

In order to analyse statistically significant correlations between leaders positive psychological resource factors and additional variables (age, gender, work experience - number of years, education, level of responsibility) shown in Table 1 further, we divided the sample into gradation classes based on work experience, responsibility level and education (see Appendix 1 Table 1) and performed univariate analysis of variance with Scheffe Post -hoc test (see Appendix 1 Table 2).

Univariate analysis of variance results suggests that cognitive wisdom dimension results have significant relations with education level $(\mathrm{F}=3.21 ; p=0.046)$ and education effect on wisdom cognitive dimension can be evaluated as medium $\eta^{2}=0.07$, because $\eta^{2}>0.06$. However Scheffe Post-hoc test results did not show significant differences in wisdom cognitive dimension average scores between education gradation classes.

In turn, work experience has significant relations $(\mathrm{F}=3.91 ; p=0.02)$ with resilience results and work experience effect on resilience can be valued as medium $\eta^{2}=0.09\left(\eta^{2}>0.06\right)$. Scheffe Post-hoc test results show that there are significant differences $(p=0.034)$ in resilience results between group of work experience up to 10 years $(n=16)$ and group of work experience more than 20 years $(n=22)$ (see Appendix 1 Table 3 and Figure 2).

Figure 2 shows different work experience level effect on resilience results. It is interesting to note that increasing work experience results in decreasing resilience results.

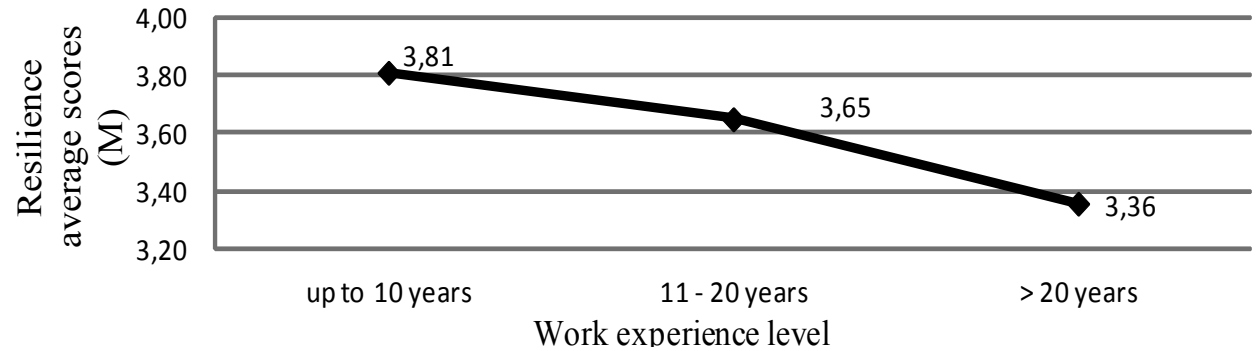

Figure 2: Resilience results in leaders sample $(\mathrm{N}=83)$ based on work experience level.

In order to investigate if there are statistically significant differences between two groups of leaders - female $(n=57)$ and male $(n=26)$, Mann-Whitney test was performed (see Table 3 ).

Mann-Whitney test results indicate that there are no statistically significant differences in both groups - female and male leader groups. 


\section{Table 3. Descriptive Statistics and Mann-Whitney test results of female and male leader groups.}

\begin{tabular}{ccccccc}
\hline & \multicolumn{5}{c}{ Gender } & \\
\cline { 2 - 5 } Variable & $\begin{array}{c}\text { Female leader group } \\
(\mathbf{n = 5 7 )}\end{array}$ & $\begin{array}{c}\text { Male leader group } \\
\text { (n=26) }\end{array}$ & U value & p value \\
\cline { 2 - 5 } & $\mathbf{M}$ & $\mathbf{S D}$ & $\mathbf{M}$ & $\mathbf{S D}$ & & \\
\hline Resilience & 3.53 & 0.55 & 3.75 & 0.50 & 557.50 & 0.07 \\
General self-efficacy & 36.02 & 3.56 & 37.35 & 4.33 & 604.00 & 0.18 \\
Cognitive dimension & 3.38 & 0.41 & 3.30 & 0.48 & 692.50 & 0.63 \\
Reflective dimension & 3.56 & 0.40 & 3.65 & 0.34 & 626.00 & 0.26 \\
Affective dimension & 3.18 & 0.45 & 3.11 & 0.47 & 693.50 & 0.64 \\
Total wisdom score & 3.37 & 0.33 & 3.35 & 0.33 & 711.00 & 0.77 \\
\hline
\end{tabular}

Note. Notations: M - Mean, SD - Standard Deviation. U - Mann-Whitney U critical value.

In order to investigate if there are statistically significant differences between two groups of leaders with high general self-efficacy and low general self-efficacy in wisdom, resilience and selfefficacy scores, the sample was divided into two groups based on self-efficacy median $(\mathrm{Me}=37.00)$ results: lower self-efficacy leader group (self-efficacy scores $<37$ ) and higher self-efficacy leader group (self-efficacy scores $>37$ ). Differences were tested with Mann-Whitney test (see T able 4).

Results in Table 4 show that the higher self-efficacy leader group have higher results in all variables compared with the lower self-efficacy leader group. However, Mann-Whitney test results indicate that statistically significant differences in both groups are only in resilience scores and that wisdom reflective dimension differences are on statistical significance border $(p=0.05)$.

Table 4. Descriptive Statistics and Mann-Whitney test results for lower selfefficacy leader group $(n=36)$ and higher self-efficacy leader group $(n=47)$.

\begin{tabular}{cccccccc}
\hline \multirow{2}{*}{ Variable } & \multicolumn{2}{c}{$\begin{array}{c}\text { Lower self-efficacy } \\
\text { leader group }(\mathrm{n}=36)\end{array}$} & \multicolumn{2}{c}{$\begin{array}{c}\text { Higher self-efficacy } \\
\text { leader group }(\mathrm{n}=47)\end{array}$} & U value & p value \\
\cline { 2 - 5 } & $\mathbf{M}$ & $\mathbf{S D}$ & $\mathbf{M}$ & $\mathbf{S D}$ & & \\
\hline Resilience & 3.31 & 0.48 & 3.83 & 0.47 & 375.00 & 0.00 \\
Cognitive dimension & 3.28 & 0.46 & 3.41 & 0.40 & 700.00 & 0.18 \\
Reflective dimension & 3.49 & 0.38 & 3.66 & 0.36 & 633.50 & 0.05 \\
Affective dimension & 3.10 & 0.38 & 3.21 & 0.46 & 707.00 & 0.20 \\
Total wisdom score & 3.29 & 0.34 & 3.43 & 0.31 & 677.00 & 0.12 \\
General self-efficacy & 33.03 & 2.65 & 39.04 & 2.23 & -- & 0.00 \\
\hline
\end{tabular}

Note. Notations: M - Mean, SD - Standard Deviation. U - Mann-Whitney U critical value.

Further analysing two leader groups - lower self-efficacy leader group and higher self-efficacy leader group we performed Spearman correlation. Correlation results are displayed in Table 5.

Table 5 shows that lower self-efficacy leader group does not have statistically significant relations between resilience, self-efficacy and wisdom dimensions. 
In contrast the higher self-efficacy leader group have statistically significant relations between resilience and wisdom reflective dimension and at trends level have relations between resilience and wisdom total score $(p=0.054)$, and total wisdom score and general self-efficacy $(p=0.086)$.

\section{Table 5.}

\section{Spearman correlations between resilience, general self-efficacy and wisdom dimensions in lower self-efficacy leader group $(n=36)$ and higher self-efficacy leader group $(n=47)$.}

\begin{tabular}{ccccccc}
\hline Variables & $\mathbf{1 .}$ & $\mathbf{2 .}$ & $\mathbf{3 .}$ & $\mathbf{4 .}$ & $\mathbf{5 .}$ & $\mathbf{6 .}$ \\
\hline 1. Resilience & -- & 0.19 & 0.20 & $0.35^{*}$ & 0.20 & 0.28 \\
2. General self-efficacy & 0.12 & -- & 0.23 & 0.09 & 0.24 & 0.25 \\
3. Cognitive dimension & -0.13 & 0.12 & -- & $0.51^{* *}$ & 0.26 & $0.74^{* *}$ \\
4. Reflective dimension & 0.03 & 0.11 & $0.54^{* *}$ & -- & $0.39^{\star *}$ & $0.80^{\star *}$ \\
5. Affective dimension & -0.08 & 0.20 & $0.34^{*}$ & 0.23 & -- & $0.73^{\star *}$ \\
6. Total wisdom score & -0.12 & 0.14 & $0.82^{* *}$ & $0.71^{* *}$ & $0.71^{* *}$ & -- \\
\hline
\end{tabular}

Note. ${ }^{*} p<0.05 ;{ }^{* *} p<0.01$. The top of the table represents higher self-efficacy leader group results, the lower part of the table - lower self-efficacy leader group results.

\section{Conclusions}

The main purpose of this study was to examine relationship between positive psychology resources - resilience, general self-efficacy and wisdom dimensions - cognitive, reflective and affective dimension and to examine differences in positive psychology resources between two groups of leaders - with higher general self-efficacy and lower general self-efficacy. We also investigated whether there are correlations between leader's positive psychological resource factors and additional variables (age, gender, work experience - number of years, education, level of responsibility)

The research results show that:

1. There is a statistically significant relationship between general self-efficacy and resilience. This result supports study results (Edward, Welch, \& Chater, 2009) about resilience, which confirm that self-efficacy and self-reliance are important factors that contribute to a sense of resilience.

2. There are statistically significant relationships between general self-efficacy and total wisdom scale, cognitive wisdom dimension and reflective wisdom dimension. We found no direct studies that confirm or deny the results, but it is possible that the following data indicate subordinate relationship, i.e., Hannah et al. (Hannah, Avolio, Luthans, \& Harms, 2008) notes that it is known that self-efficacy influences both the extent and manner in which leaders employ cognitive abilities (Wood \& Bandura, 1989a).

3. There is statistically a significant relationship between resilience and wisdom reflective dimension and at trends level have relationship between resilience and wisdom total score. This result coincides with the theory that resilience is an important component of wisdom (Jeste, Ardelt, Blazer, Kraemer, Vaillant, \& Meeks, 2010).

4. Between leader groups of different work experience levels ( $<10$ years and $>20$ years) exist significant differences in how they affect resilience scale indicators, i.e., resilience scores are lower for the leaders with work experience $>20$ years. Possibly this effect can be explained with resilience studies (Rutter, 2006), which suggest that stress negative impact on neural processes can impact resilience, assuming that leaders with work experience $>20$ years have had more stressful experience compared to leaders with work experience $<10$ years.

5. There is statistically a significant relationship between education level and wisdom cognitive dimension, which agrees to previous research results (Ardelt, 2010 as mentioned in Bergsma, Ardelt, 2012), which confirm positive association between higher vocational or university education and the cognitive wisdom dimension (Bergsma, Ardelt, 2012). 
6. There were no statistically significant differences in levels of psychological resources - general self-efficacy, resilience and wisdom dimensions between female leader group and male leader group. Results re: wisdom dimensions and gender agree with three dimensional wisdom scale (3D-WS) author's (Ardelt, 2003) results, which show that $3 \mathrm{D}-\mathrm{WS}$ is not related to gender.

7. There are differences in levels of psychological resources between higher general selfefficacy leaders group and lower general self-efficacy leaders group. Higher general self-efficacy leaders showed higher results in all tested psychological resources and statistically significant differences between two groups were reported in resilience, while difference in reflective wisdom dimension is located on the border of statistical significance $(p=0,05)$. Results suggest that lower self-efficacy leaders would be less able to adapt to uncertainty, and/ or bounce back or recover from stress and might be less able to have positive change and progress, compared to high general self-efficacy leaders. Research results suggest that high level general self-efficacy is related to higher levels of resources - resilience and wisdom.

\section{References}

Anderson, D. W., Krajewski, H. T., Goffin, R. D., Jackson, D. N. (2008). A leadership self-efficacy taxonomy and its relation to effective leadership. The Leadership Quarterly, 19, 595-608.

Ardelt, M. (2003). Empirical Assessment of a Three-Dimensional Wisdom Scale. Research on Aging, 25 (3), 275-324.

Ardelt, M. (2004). Wisdom as Expert Knowledge System: A Critical review of a Contemporary Operationalization of an Ancient Concept. Human Development, 47, 257-285.

Avolio, B. J., Walumbwa, F. O., Weber, T. J. (2009). Leadership: Current theories, research, and future directions. Annual Review of Psychology, 60, 421-449.

Baldwin, J., Maldonado, N. L., Lacey, C. H., Efinger, J. (2004). Resilient Women Leaders: A Qualitative Investigation. EBSCHO Online Submission, Paper presented at the Annual Meeting of the American Educational Research Association (AERA) (85th, San Diego, CA, Apr 12-16, 2004).

Chen, G., Gully, S. M., Eden, D. (2009). Validation of a New General Self-Efficacy Scale. Organizational Research Methods, 4 (1), 62-83.

Cohen, J. (1988). Statistical Power Analysis for the Behavioural Sciences. Second Edition. Lawrence Erlbaum Associates, Publishers. Hillsdale, New Jersey.

Edward, K., Welch, A., \& Chater, K. (2009). The phenomenon of resilience as described by adults who have experienced mental illness. Journal of Advanced Nursing, 65 (3), 587-595.

Froman, L. (2010). Positive psychology in the workplace. Journal of Adult Development, 17 (2), 59-69.

Gorgievski, M. J., Halbesleben, J. R. B., Bakker, A. B. (2011). Expanding the boundaries of psychological resource theories. Journal of Occupational and Organizational Psychology, 84, 1-7.

Hannah, S. T., Avolio, B. J., Luthans, F., Harms, P. D. (2008). Leadership efficacy: Review and future directions. The Leadership Quarterly. DigitalCommons@University of Nebraska - Lincoln. Management Department Faculty Publications, Paper 5.

Hendricks, J. W., Payne, S. C. (2007). Beyond the Big Five: Leader Goal Orientation as a Predictor of Leadership Effectiveness. Human Performance, 20 (4), 317-343.

Jeste, D. V., Ardelt, M., Blazer, D., Kraemer, H. C., Vaillant, G., Meeks, T. W. (2010). Expert Consensus on Characteristics of Wisdom: A Delphi Method Study. The Gerontologist, 50 (5), 668-680.

Luthans, F., Avolio, B. J., Avey, J. B., \& Norman, S. M. (2007). Positive psychological capital: Measurement and relationship with performance and satisfaction. Personnel Psychology, 60, 541-572.

Luthans, F., \& Youssef, C. M. (2007). Emerging positive organizational behavior. Journal of Management, 33, 321-349.

Luthans, F., Norman, S. M., Avolio, B. J., Avey, J. B. (2008). The mediating role of psychological capital in the supportive organizational climate-employee performance relationship. Journal of Organizational Behavior, 29, 219-238. 
Luszczynska, A., Gutiérrez-Doña, B., Schwarzer, R. (2005). General self-efficacy in various domains of human functioning: Evidence from five countries. International Journal of Psychology, 40 (2), 80-89.

Küpers, W., Statler, M. (2008). Practically wise leadership: toward an integral understanding. Culture and Organization, 14 (4), 379- 400.

Scholz, U., Gutiérrez-Doña, B., Sud, S., \& Schwarzer, R. (2002). Is general self-efficacy a universal construct? Psychometric findings from 25 countries. European Journal of Psychological Assessment, 18 (3), 242-251.

Schwarzer, R., \& Hallum, S. (2008). Perceived teacher self-efficacy as a predictor of job stress and burnout: Mediation analyses. Applied Psychology: An International Review, 57, 152-171.

Smith, B. W, Dalen, J., Wiggins, K., Tooley, E., Christopher, P., Bernard, J. (2008). The Brief Resilience Scale: Assessing the Ability to Bounce Back. International Journal of Behavioral Medicine, 15, 194-200.

Wei, R. R., Yip, J. (2008). In focus/leadership wisdom - Some sage advice for leaders. Leadership in Action, $28(4), 18-22$.

Wood, R., \& Bandura, A. (1989). Impact of conceptions of ability on self-regulatory mechanisms and complex decision making. Journal of Personality and Social Psychology, 56, 407-415.

\section{Appendix 1}

\section{Table 1. Gradation classes based on work experience, responsibility level and} education.

\begin{tabular}{llc}
\hline \multicolumn{1}{c}{ Factor } & \multicolumn{1}{c}{ Gradation classes } & Number of Respondents \\
\hline \multirow{3}{*}{ Work experience } & 0 -10 years & 16 \\
& $11-20$ years & 45 \\
& $>21$ years & 22 \\
& Total & 83 \\
\hline \multirow{4}{*}{ Responsibility level } & Up to 5 employees & 37 \\
(number of subordinate staff) & $6-20$ employees & 25 \\
& $>20$ employees & 21 \\
& Total & 83 \\
\hline \multirow{3}{*}{ Education } & Secondary professional /uncompleted higher education & 4 \\
& Bachelors degree / higher professional & 31 \\
& Master & 48 \\
\hline
\end{tabular}

Table 2. Univariate analysis results and effect of education, work experience and responsibility level on resilience, general self-efficacy and wisdom dimensions.

\begin{tabular}{cllccc}
\hline $\begin{array}{c}\text { Independent } \\
\text { variable }\end{array}$ & Dependent variable & df & F & p-value & $\boldsymbol{\eta}^{2}$ \\
\hline \multirow{5}{*}{ Education } & Resilience & 2 & 0.13 & 0.88 & 0.003 \\
& General self-efficacy & 2 & 0.24 & 0.79 & 0.006 \\
& Cognitive dimension & 2 & 3.21 & 0.05 & 0.074 \\
& Reflective dimension & 2 & 2.86 & 0.06 & 0.067 \\
& Affective dimension & 2 & 0.52 & 0.60 & 0.013 \\
& Total wisdom score & 2 & 1.70 & 0.19 & 0.041 \\
\hline
\end{tabular}


ISSN 2029-8587 PROBLEMS OF PSYCHOLOGY IN THE $21^{\text {st }}$ CENTURY Volume 5, 2013

\begin{tabular}{|c|c|c|c|c|c|}
\hline $\begin{array}{l}\text { Independent } \\
\text { variable }\end{array}$ & Dependent variable & df & $F$ & $p$-value & $\eta^{2}$ \\
\hline \multirow{6}{*}{ Work experience } & Resilience & 2 & 3.91 & 0.02 & 0.089 \\
\hline & General self-efficacy & 2 & 1.12 & 0.33 & 0.027 \\
\hline & Cognitive dimension & 2 & 1.21 & 0.31 & 0.029 \\
\hline & Reflective dimension & 2 & 2.08 & 0.13 & 0.049 \\
\hline & Affective dimension & 2 & 0.85 & 0.43 & 0.021 \\
\hline & Total wisdom score & 2 & 1.17 & 0.32 & 0.028 \\
\hline \multirow{6}{*}{ Responsibility level } & Resilience & 2 & 0.71 & 0.49 & 0.018 \\
\hline & General self-efficacy & 2 & 2.46 & 0.09 & 0.058 \\
\hline & Cognitive dimension & 2 & 0.92 & 0.40 & 0.022 \\
\hline & Reflective dimension & 2 & 0.82 & 0.45 & 0.020 \\
\hline & Affective dimension & 2 & 1.33 & 0.27 & 0.032 \\
\hline & Total wisdom score & 2 & 0.68 & 0.51 & 0.017 \\
\hline
\end{tabular}

Note. $N=83$.

Table 3. Scheffes Post Hoc test multiple comparisons of resilience means between work experience levels.

\begin{tabular}{ccccc}
\hline (I) Work experience level & $(\mathrm{J})$ Work experience level & Mean difference $(\mathrm{I-J})$ & Std. Error & Sig. \\
\hline \multirow{2}{*}{ Up to10 } & $11-20$ & 0.1644 & .01521 & 0.560 \\
& $>20$ & $0.4564^{*}$ & 0.1717 & 0.034 \\
\multirow{2}{*}{$11-20$} & up to 10 & -0.1644 & 0.1521 & 0.560 \\
& $>20$ & 0.2921 & 0.1360 & 0.106 \\
$>20$ & Up to10 & $-0.4564^{*}$ & 0.1717 & 0.034 \\
& $11-20$ & -0.2921 & 0.1360 & 0.106 \\
\hline
\end{tabular}

${ }^{*} p<0.05$

Advised by Vadim N. Kolesnikov, Karelian State Pedagogical Academy, Republic of Karelia, Russia

Received: February 26, 2013

Accepted: March 26, 2013

Guna Svence $\mathrm{PhD}$ in Psychology, Professor, Riga Teacher Training and Education Management Academy, Latvia.

E-mail: guna.svence@rpiva.lv

Website: http://www.rpiva.Iv/index.php?mh=izgl_soc_psih

Vineta Greaves Board Member, VCG SIA ("VCG"), Baznīcas iela 13/4, Riga, Latvia

E-mail: vineta.grivza@vcg.Iv

Website: http://www.vcg.Iv/lv/cv-vineta.html 